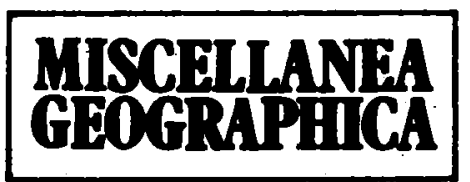

WA R S A W A 1988

Ewelina Kantowicz

\title{
RELATIONS BETWEEN MAN AND ENVIRONMENT IN RESEARCH AND TEACHING OF REGIONAL GEOGRAPHY
}

The name of this discipline-regional geography-unambiguously indicates that a region is its subject of research and teaching. In spite of this clear suggestion coming from its name, the development of this discipline, both in the past and at present, has encountered multiple controversies related to its subject, its place among other geographical disciplines and its value. It would be aimless to repeat once again the old, often justified reproaches addressed to regional geography and to discuss them here. New trends in regional geography were presented against the background of developments in the views of geographers as to this discipline during, consecutively, the conference devoted to methodological problems of Polish geography organized in Rydzyna and during the IGU congress in Paris (E. Kantowicz and M. Skotnicki, 1983, 1984). In the present paper, which continues and develops these previous considerations I would like to present a research concept and educational programme consistent with it, which is different from the existing traditions.

The above-mentioned concept suggests that regional geography should lead to the synthesis of relations existing between natural environment and human activity. This concept appeared within the Warsaw centre of regional geography and was first presented in public during the conference of geographers in 1970 (B. Dumanowski, 1981). Out of the two traditional foundations of regional geography, that is area/region and comprehensiveness, the latter understood as the tendency towards linking natural phenomena with the socio-economic ones-the approach presented emphasizes just this synthesis, without necessity of consideration of a region as the centre organizing the studies. Description of a region and identification of its specifics is, therefore, to an even lesser degree goal of work in the approach presented.

An especially advantageous climate and an increase of demand for development of research on natural environment and its relations with human activity were created by growing anthropogenic pressure and 
ecological threats connected with it, which locally take on the form of catastrophes or ecological crises. Biological productivy of the Earth is based upon the stable and regular interrelations among such factors as solar energy, soils, atmosphere, hydrosphere and biosphere. As long as man does not intervene in this complex system, it acts as a self-regulating, dynamic mechanism producing biomass and determining the features of soil and hydrosphere. Human intervention introduces changes, which can bring benefits, especially when relations existing between natural conditions and human activities are well understood. When use of natural resources is improper, environment undergoes degradation. The scale of this problem is enormous, as for instance illustrated by the estimates as to the surfaces of downgraded soils. Total surface of the Earth's downgraded soils which once were productive is at present greater than the whole surface of currently cultivated lands, according to V. A. Kovda (1979). There are various reasons for that: erosion, desertification, salinization, transportation, infrastructure and construction Many phenomena, such as increase of atmospheric pollution or destruction. of tropical forest, lead to changes which should be considered on a global scale. Importance of all these problems is reflected by the development of international cooperation within the framework of such research projects and programme as "Man and Biosphere" (MAB), "International Hydrological Programme" (IHP), "International Biological Programme" (IBP), the programme of the Commission for Agricultural Meteorology and a number of others.

Speaking about man-environment relations one should not consider just one direction of the dependences involved, that is, the one best acknowledged and leading to changes disadvantageous to man. Relations considered are, in fact, bilateral. The question of influence of natural environment on human condition, which is of interest to geographers, was to a large extent left aside after the period of the so-called geographical determinism. Views which then gained popularity stated that as productive forces increase, human dependence upon natural environment decreases. Still, however, as can be concluded on the basis of sharpness and scale of problems related to subsequent ecological crises, one can speak not so much of decreasing influence as of changing nature of relations. Nowadays, perhaps under the influence of geographers of the Far East, this direction of dependence is also more and more often the object of lively interest, to mention the work of two geographers active in the U.S.A. - Yi-Fu Tuan and Hideo Suzuki.

In the context of background depicted here a region turns out to be a concept of limited utility. Other questions of paramount theoretical and practical importance emerged in the meantime. The list of these questions, given below, without any hierarchical ranking, is open, so that the items given are just an illustration: 
(1) Significance of diversity - differentation of natural environment for the functioning of ecosystems and for the man-environment relations;

(2) "weak links" in the system of man-environment interrelations, i.e. the ones in which equilibrium of a system is most easily destroyed, and small changes are transformed into big ones (influences of limiting factors, with special emphasis on extremal environments);

(3) natural and anthropogenic changes in natural environment and their connection with natural conditions of human activity (natural functional barriers);

(4) perception of natural environment changing in time and space;

(5) continuous or threshold-like nature of influence of natural environment on man.

Some of the problems mentioned here, such as, for instance, the question concerning significance of diversity of environment, are examples of fundamental theoretical problems deemed to be necessarily solved in order to improve ecological management of territories (B. Golley 1984). They were commented upon in the survey of research results from more than ten years of the MAB programme and other international research programmes related to the ecological trend (Ecology in Practice 1984). Finally, it should be noted that studies of relations between man and his environment as a whole are theoretical basis for practical activities aiming at preparation of all kinds of assessments of environment adequacy and quality with regard to definite utilization goals. One should first know how environment influences a definite sphere of human activity and the man himself in order to be able to say what is the ultimate suitability of the environment.

New research goals of regional geography imply new requirements in university teaching with regard to this discipline, A student choosing regional geography as specialization at the University of Warsaw is first of all being acquainted with the problems and research methods regarding the relations between human activity and natural conditions. Thus, a student gains definite skills in approaching problems of socioeconomic development in a global and regional perspective. It is in this sense that a student is being prepared to work in the domain of protection and management of the environment, in geographic and cartographic publishing houses, as well as in institutions connected with cooperation with other countries and in education.

Thus outlined profile of a regional geography specialization graduate, who should be able to make syntheses, that is to creatively use the results produced by the research conducted within different geographical disciplines, puts emphasis on the requirement of understanding the fundamental natural and socio-economic processes. This goal is, certainly, being attained in the course of the whole 5-year period of studies at the faculty of geography. Within the specialization programme 
(see Appendix for the list of subjects taught) one can also find a general, evolutionary approach to the three main problems: nature, its structure and evolution, geography of man and of socio-economic development, various aspects of relations between nature and human activity.

The course on "Evolution and structure of nature", founded upon an initial more detailed knowledge of questions related to particular elements of the environment, gained through the lectures in geology, geomorphology, climatology, etc. - all available in the general programme of studies, concentrates on change and continual interaction among the earth phenomena and among their patterns of variation. Thus, for instance, in the evolution of lithosphere questions of plate tectonic in global scale and on regional examples are considered, providing explanations for major structural features of the Earth's surface during the past 200 million years, as well as problems of mutual relations of internal and external processes with particular attention paid to various time scales connected with both these groups of processes.

In the lectures on "Geography of man" efforts were made not to repeat in the choice of problems the scope of the lecture in economic geography, traditionally given in Poland, on the one hand, and to fill the gap which was created with respect to questions other than economic, on the other hand. The problem area of the lectures is, therefore, the broadly conceived culture of societies. Such problems are considered as the relation of particular disciplines (history, historiosophy, knowledge of culture, etc.) and of their research concepts to theoretical and methodological concepts of geography, the main stages of biological and cultural evolution of man, or old and new concepts of progress, development and economic growth.

The subject "Nature and society" has the least developed basis in terms of theories of the institutionalized science, but the evolutionary point of view, observed in all the three outlined lectures, makes it possible to present a certain philosophical and methodological reflection, important for consideration of the man-environment interaction. This reflection encompasses such questions as: philosophy of relation of man to nature, changing over time and space, as well as scientific concepts being shaped under the influence of such philosophy, the question of causal relation, coincidence and randomness with regard to natural process and to processes connected with human beings, the question of co-dependence of elements of the two systems and their hierarchization, and finally the problems of the very relations-their nature and mechanism.

Relations can be treated through evaluation of common variability of the two phenomena and then correlational methods and techniques are adequate, allowing measurement and detection of coincidence of these phenomena. One can also, and this is the tendency in contemporary geographic 
studies (R.J. Johnston, 1983), try to gain a deeper insight and to search for the mechanism of the relation, that is for the process leading to co-appearance of the phenomena. The mechanisms may be of psychological (e.g. perception, individual decisions), social (e.g. innovation diffusion), economic (e.g. demand and supply forces), political (e.g. activity of the political decision makers), or natural (e.g. processes of degradation of the environment or genetic and phenotypic adaptation) character. In fact, these processes most often act simultaneously, and the existing knowledge of their mutual connections, as well as of relations with the environment is highly insufficient. Hence, in the research and in teaching correlational methods are most often applied, and only in the interpretation of results general or detailed knowledge of the mechanisms of the relevant processes is being referred to.

\section{APPENDIX}

List of subjects taught at the regional geography specialization:

(a) obligatory

evolution and structure of nature, geography of man, nature and society, detailed methodology of regional geography, natural resources, M.A. seminar, specializing practical exercises (carried out in planning or scientific institutions, publishing houses etc., altogether 9 weeks), master's workshop;

(b) facultative

evaluation of natural environment, natural boundaries and human activity, regionalization problems, certain demographic and urbanization problems of the world, contemporary population migrations, certain problems of political and social geography, problems of equatorial, desert, mediterranean, temperate, mountainous, polar and the Third World areas.

\section{REFERENCES}

D u m a n owski, B., 1981, „Geografia regionalna jako dyscyplina badawcza”. Regional geography as research discipline, Przeglad Geogr., LIII, 1, pp. 87-94.

Ecology in Practice, 1984, F. di Castri, F.W.G. Baker, M. Madley, (eds) Tycooly International Publishing Ltd., Dublin/UNESCO, Paris. Part I: Ecosystem Management. Part II: Social Response.

Gol1ey, F.B., 1984, "Land management in the humid and subhumid tropics", in: Ecology in Practice, F. di Castri, F.W.G. Baker, M. Madley, (ees), Tycooly International Publishing Ltd., Dublin/UNESCO, Paris, pp. 29-57.

J ohnst o n, R.J., 1983, "Resource analysis, resource management and the integration of physical and human geography", Pro gress in physical geography, 7, 1, pp. pp.127-146. 
K a n towicz, E. and Skotnicki, M., 1983, Glówne problemy i tendencje w geografii regionalnej (Main problems and trends in regional geography), in: Ogólnopolska konferencja geograficzna .,Podstawowe problemy metodologiczne rozwoju polskiej geografii", Rydzyna, June 27-30, 1983, mineograph.

$\mathrm{K}$ ant ow icz, E. and Skotnicki, M., 1984, "Trends in regional geography", Miscellanea Geographica, Warszawa, pp. 153-161.

Kovda, V.A., 1979, "Soil reclamation and food production", in: Food. Climate and Man, Biswas and A.K. Biswas, (eds). J. Wiley, New York Chichester Brisbane Toronto, pp. 159-186. 